\title{
LA FORMACIÓN PROFESIONAL DE LOS ARCHIVISTAS, UNA EXIGENCIA SOCIAL*
}

\author{
Celia Ramírez López**
}

\section{Resumen}

Es urgente una formación profesional de los archivistas que proporcione los fundamentos teóricos requeridos para un óptimo ejercicio, y no busque la profesionalización solamente para lograr el status que le da el título y obtener el reconocimiento social del que hoy carece. Debe incluirse en la formación profesional el saber acumulado a través del tiempo en la práctica archivística mundial, al margen de la institución escolar. En México, los responsables de los archivos no tienen estudios profesionales de archivística avalados por una institución de educación superior. Estamos en el momento histórico ideal para promover el desarrollo profesional de los archivistas, ya que se han creado leyes e instituciones que lo exigen, pues la problemática de los archivos ha crecido notablemente.

Palabras clave: profesión, educación superior, acreditación, credencialismo.

\section{Abstract}

The professional education of archivists is necessary to supply the theoretical bases for their optimal exercise. Not only to achieve the diploma status for the social acknowledgment it currently lacks. This education must include the accumulated knowledge through time in the archivist practice worldwide, aside the educational institution. In Mexico people responsible for archives lack professional studies backed by high education institutions. At this moment because of the

\footnotetext{
* La autora presentó una versión de este trabajo como ponencia en el Foro Nacional Aportación de las Instituciones de Educación Superior Hacia la construcción de una Ley General de Archivos, que se realizó en la ciudad de Pachuca, Hidalgo, el 24 noviembre de 2014.

** Instituto de Investigaciones sobre la Universidad y la Educación (IISUE) de la UNAM.
} 
remarkable growth of archives the new laws and institutions demand the promotion and the professional development of archivists.

Keywords: profession, high education, accreditation, credentialism.

Ante la preocupación y urgencia de profesionalizar algunas tareas, vale la pena una breve reflexión sobre la razón de ser y el origen de las profesiones. Muchas de las que hoy conocemos nacieron en universidades, pero otras tuvieron origen en ocupaciones de diversa índole y desarrollaron su propia tradición y necesidades. Para ejercer su práctica no necesitaban estudios y mucho menos acreditar sus competencias. Sin embargo, las exigencias de la modernidad y la ciencia obligaron a fundamentar sus prácticas, por lo que buscaron como un camino seguro su incorporación a instituciones de enseñanza superior donde cultivaban el conocimiento científico y, algo muy importante, se otorgaban títulos para ejercer.

El camino no fue fácil ya que algunas ocupaciones, que se consideraban oficios no tenían nada que ver con lo que se enseñaba en la universidad antigua, pues en ella "se cultivaba la mente" a diferencia de la enseñanza de los oficios en los que prevalecía la educación artesanal. Ésta no sólo era suficiente, sino valorada socialmente, pues bastaba con saber que quienes enseñaban los oficios los dominaban con maestría. Los "maestros" conocían la práctica y la desempeñaban con perfección; con experiencia dominaban los secretos, los fundamentes teóricos y la razón de ser del oficio. El aprendizaje artesanal culminaba cuando el aprendiz lograba dominar el conocimiento necesario para ejercer el oficio sin ayuda de su mentor. Esto lo convertía en "maestro".

Aunque esta educación cumplió su función de transmisión de saberes y habilidades por mucho tiempo, la modernidad trajo la profesionalización que significó la identificación del individuo con la institución universitaria, considerando que, sólo a través de ella una ocupación adquiriría estatus académico, prestigio social y reconocimiento.

Por otra parte, el desarrollo científico y tecnológico obligó a las universidades a volver su atención a ocupaciones que no había atendido, 
como sucedió con los colleges ingleses que incorporaron las ingenierías ante el avance de la revolución industrial. ${ }^{1}$

El capitalismo otorgó alto valor económico a las profesiones que tenían el estatus que les daba la acreditación otorgada por la educación superior, por tanto, redundó en mejor retribución económica a quien poseía un título universitario. En este tenor una de las funciones del título fue, y quizás ha sido, dar carácter de propiedad al saber profesional. La posesión de éste, además de otorgar licencia para ejercer, excluía del ejercicio a los que no lo poseían impidiendo el paso a los "no iniciados". Esto acabó por descalificar el saber común y la experiencia que proporcionaba la educación artesanal; asimismo, fue una buena razón para que los gremios buscaran el reconocimiento académico de sus ocupaciones.

\section{La profesión de archivista}

Los archivistas en la actualidad, a pesar de tener una larga historia, así como práctica, estamos en coyuntura y tenemos la intención de buscar la profesionalización para quienes no cuenten con ella logrando un estatus académico y reconocimiento social, lo que hará más rentable la profesión. Aunque esto será, indudablemente, una consecuencia de la profesionalización, tenemos -como responsables y conocedores de la importancia y urgencia social de la tarea archivística- la obligación de presentar ante la sociedad y sus dirigentes la necesidad y el impacto que tendría el desarrollo de la formación profesional de los archivistas.

La profesión se ha definido como un saber especializado, necesario socialmente, sobre un campo determinado, con fundamento teórico que le posibilite normar la práctica. Todo, apreciado socialmente y, por lo tanto, retribuido económicamente. ${ }^{2}$

El ámbito de las universidades es la transmisión de la ciencia, de forma tal que la razón fundamental para incluir una carrera en ellas es proporcionar los fundamentos teóricos requeridos para su ejercicio. Sin embargo, no ha ocurrido siempre así; frecuentemente se ha limitado la legitimación

1 Phillip, Elliot, Sociología de las profesiones.

2 Idem. 
académica a poseer una acreditación para ejercer una profesión, o dar a los títulos un carácter de propiedad excluyendo del ejercicio profesional a quienes no lo poseen.

Así, los factores que han promovido la búsqueda de acreditación académica de algunas profesiones han sido, en ocasiones, externos a la ciencia y a la pertinencia social. ${ }^{3}$

Frecuentemente se busca la inserción de una práctica o un saber en la enseñanza superior para alcanzar prestigio, o con la ilusión de que, sujetarse a los requisitos de las instituciones académicas, garantizará la calidad, la eficiencia y el prestigio requerido para la valoración social y económica.

Con este motivo, se privilegian las aprobaciones oficiales, el prestigio de la institución, el número de años de estudio, el profesorado con grados (no importa la especialidad) y, frecuentemente, en la constitución de una nueva carrera se da poca importancia o se ignora la experiencia, la reflexión y el conocimiento acumulado a través de años de ejercicio, porque no provienen de personas con acreditación académica.

Es necesario tomar en cuenta -en el marco conceptual de las nuevas carreras profesionales- el saber desarrollado en el ejercicio profesional. Pero si este ejercicio no se ha revisado, analizado y evaluado para ver su impacto y pertinencia en el ámbito de su competencia, la formación profesional no será sino la fórmula de transmisión de un ejercicio pobremente razonado que no hará sino reproducir una práctica desgastada.

Si consideramos que profesionalizar es más que legitimar una profesión a través de la acreditación escolar y que, particularmente en nuestra materia, en que mucho del saber archivístico se ha desarrollado al margen de la institución escolar, necesariamente tenemos que incluir el saber acumulado a través del tiempo en la práctica archivística mundial, lo cual enriquecerá la formación escolar impartida hasta la fecha.

Los archivistas tenemos razones de sobra para buscar el desarrollo de la profesionalización y estamos en un momento histórico de México para promoverlo.

3 Este fenómeno que afectaba a la formación de varias profesiones fue trabajado por pedagogos en los años setenta del siglo pasado, se le denominó "credencialismo". 
Hemos rebasado las épocas en que los archivistas eran "encargados" de conservar papeles, sobre todo en las organizaciones, tarea que no requería un gran trabajo mental, al fin y al cabo, era un oficio que podía realizar quien bien supiera leer, escribir y contar adecuadamente. Todos los problemas prácticos y teóricos que surgían en los archivos por parte de los responsables sin la conciencia del conocimiento científico que implicaban y sin espacio para la reflexión teórica.

Por necesidades o urgencias institucionales la responsabilidad de los archivos recaía frecuentemente en personas con diferentes niveles de formación, con bajo prestigio laboral, académico y cuyo trabajo fue desarrollándose sin más comprobación que la eficiencia que se les reconocía y sin posibilidades de resolver problemas que rebasaran aquello que sabían por la práctica, careciendo muchas veces de principios teóricos y desconociendo el objetivo final y el valor institucional de un trabajo al que estaban entregados.

Cada vez se hizo más evidente que la administración de los archivos requería de personal con una formación sólida que permitiera dirigirlos, ya que los responsables, en muchos casos, y por causas ajenas a ellos, no tenían las herramientas teóricas y técnicas para hacerlo, ni la oportunidad para adquirirlas.

La falta de visión en relación con la realidad de los archivos en muchas instituciones ha hecho que se conviertan en un problema progresivo que se ha complicado con la administración moderna.

Paralelamente a los archivistas de oficio empezaron a acceder a los archivos profesionistas, quienes por su formación académica, profesional o su posición en las instituciones reconocían o necesitaban la información contenida en sus acervos.

Estos profesionistas, administradores, abogados, historiadores o bibliotecarios, empezaron a incursionar en el campo de los archivos recurriendo a metodologías propias de su profesión, actividades similares a la bibliotecología, cuyos fundamentos estaban acreditados y podían aplicarse sin riesgo de censura, aunque no siempre fueron los más adecuados para los archivos.

Muchos de los que han desarrollado el campo de la archivística, identificando su objeto, revisando su práctica e investigando los principios 
teóricos que la sustentan, provienen de otros campos científicos y profesionales; su estudio en otras disciplinas les proporcionó metodologías que aplicaron o adaptaron.

Además de quienes hasta ahora han trabajado y dirigido los archivos -incluso con éxito-, se necesitan profesionales de la archivística que, habiendo ejercido y analizado la práctica, aporten fundamentos teóricos y tengan idea clara respecto a la trascendencia social de su tarea.

Sin embargo, comprender y dominar las habilidades archivísticas no profesionaliza: conocer y profundizar la función social de los archivos, haciéndolos objeto de estudio y desarrollar la metodología para que cumplan esta función es labor que esperamos de los profesionales de la archivística, pues el hecho de que la archivística siga siendo una tarea secundaria, accesoria y provisional -aun en las organizaciones modernas que reconocen la importancia de la información-, se debe a que no hay suficientes teóricos que trasmitan a la sociedad su valor.

En México la mayoría de los responsables de los archivos no tienen estudios profesionales de archivística avalados por una institución de educación superior. ${ }^{4}$ El problema no es que carezcan de un título que los acredite como archivistas, sino que no cuenta con una formación sólida científica y teórica que les permita dominar los fundamentos específicos de una tarea de innegable utilidad social.

Si se pretende establecer más carreras relacionadas con la archivística, ${ }^{5}$ los archivistas tenemos que pugnar porque su currículo esté acorde con los objetivos de esta profesión y no determinado sólo por las exigencias del sistema educativo. Esto es más grave de lo que parece pues los requerimientos académicos no toman en cuenta siempre las particularidades de los diferentes ejercicios profesionales, y me atrevería a decir que esto no es privativo de la archivística.

4 Conforme con el diagnóstico realizado por el Instituto Federal de Acceso a la Información Pública (IFAI) en 2007, 56\% de los responsables de archivos no contaba con estudios de archivística, ni con experiencia profesional en ese campo. Véase Diagnóstico de la situación archivistica de las dependencias y entidades de la Administración Pública Federal, 2007, p. 34.

5 En México sólo tres instituciones imparten carreras en la materia: la Escuela Nacional de Biblioteconomía y Archivonomía, la Universidad de San Luis Potosí y parcialmente la Universidad Autónoma del Estado de México. Las instituciones de educación superior privada no han mostrado interés por estas carreras. La UNAM, sin embargo, aprobó la licenciatura en administración de archivos y gestión documental en noviembre de 2014, que se impartirá en la Escuela Nacional de Estudios Superiores Unidad Morelia (ENES). 
Aunque es una instancia ajena a la institución universitaria, el campo laboral debe ser considerado en la educación profesional, puesto que una de las razones por las cuales los alumnos eligen una profesión es para integrarse a ella al finalizar sus estudios. La institución universitaria, por su parte, tiene la responsabilidad de ofrecer las profesiones necesarias para la sociedad aunque ésta no las valore o demande en el mercado de trabajo actual.

La demanda laboral no puede ser determinante para la formación profesional porque tiene otra racionalidad; pero si las universidades no forman a los sujetos esperados puede haber desajuste entre oferta y demanda, aunque esto no indica de ninguna manera una mala formación universitaria. La tarea de promover el campo de trabajo de los archivistas no es responsabilidad de la institución sino del gremio.

Los empleadores prefieren a quien tiene la capacidad para resolver problemas, es eficaz y no cuestiona las actividades en el trabajo. Se aceptan las innovaciones siempre que no cuesten mucho tiempo y dinero, para esto no hace falta una formación teórica y universal, sino buenos técnicos, pues se piensa que los teóricos más bien "complican" las cosas. No importa que a largo plazo las propuestas de revisión o reforma sean mejores, pues son caras y requieren más recursos, gente mejor pagada y mejores instalaciones, por ende, estos proyectos se desechan, con graves consecuencias en muchos casos.

Así que, somos los archivistas quienes debemos convencer a los empleadores de la necesidad de contar con profesionales que, aun cuando al principio se eleven los costos podrán resolver los problemas a los que se enfrentan actualmente en sus archivos.

Este comportamiento de los empleadores con respecto a los profesionales, por el que podíamos sentirnos desalentados o cuestionados, no es privativo de los archivistas, sino de muchos otros profesionales.

Estamos en una transición, no caigamos en la tentación de creer que basta con tener una licenciatura o un posgrado; la tarea es más compleja y mucho más amplia. Habrá que revisar nuestra práctica a la luz de todo el avance teórico que ha tenido la archivística fuera de las instituciones de enseñanza superior. El trabajo de congresos, asociaciones, cursos, seminarios e investigaciones de nuestra especialidad ha sido grande y fructífero y ha conducido la práctica archivística contemporánea. Si 
queremos una formación profesional adecuada debemos rescatar, lo realizado por la comunidad archivística mundial a través de su práctica e integrarla a la formación profesional en materia archivística.

La lógica moderna ve la educación superior como inversión. La utilidad o relevancia del conocimiento que se enseña en las escuelas profesionales se asocia con el desarrollo social y los niveles de productividad económica. El prestigio e importancia de las profesiones se define a partir de su funcionalidad en un momento histórico concreto. El proyecto moderno plantea la importancia de la profesión por su utilidad y el ascendiente desarrollo económico y social, adscrito a un proyecto de carácter políticoinstitucional.

Afortunadamente, la coyuntura histórica de México nos favorece a través de las leyes emitidas en torno a los archivos: Ley Federal de Archivos, Ley Federal de Transparencia y Acceso a la Información Pública Gubernamental y el aparato estatal en el caso de los archivos, por ejemplo, el IFAI que recientemente cambió su denominación por Instituto Nacional de Transparencia, Acceso a la Información y Protección de Datos Personales (INAI) y las unidades de enlace, que se han desarrollado en torno a la transparencia exigen profesionales capaces de resolver los problemas urgentes a los que hoy se enfrenta la sociedad.

En algunas profesiones se reconoce la facultad de sus profesionales en la resolución de problemáticas específicas del campo de conocimiento o del fenómeno social del que se trate; por ejemplo, el médico es importante cuando está en peligro la vida, el abogado cuando están en riesgo nuestra libertad o nuestros bienes; en algunas otras no se percibe la urgencia de su intervención, salvo cuando una función que se hacía por inercia o de manera secundaria genera problemas mayores. Hoy es nuestro caso.

Actualmente, con el avance de la informática, la administración ha debido replantearse el problema del registro de la documentación en los nuevos soportes, pero se ignora o desdeña el conocimiento que desde la archivística se ha generado al respecto. Los programas para el manejo de la documentación están en manos de los expertos en computación y fallarán o se dilatarán si los archivistas no tomamos cartas en el asunto, por ello es necesario que la informática se integre en la formación de los archivistas de manera que puedan dialogar con los especialistas y hacer su labor más eficaz. 
Necesitamos aspirar no sólo a desarrollar buenos profesionistas, sino también intelectuales, expertos formados en un campo del saber más allá de lo que se considera la carrera o la profesión; por lo tanto, necesitamos posgrados que formen maestros e investigadores. Sólo así podemos "vender" a una sociedad escéptica y utilitaria el aprecio por la memoria histórica y la importancia de la administración documental en el presente.

La valoración social de la carrera puede cambiarse desde dos frentes: el ejercicio profesional y la formación profesional. Esta tarea corresponde a los archivistas en ejercicio, a los docentes y a los archivistas en formación; unos, ganando espacios en las instituciones por su labor eficaz y comprometida; otros, transmitiendo un saber cada vez más fundamentado teóricamente y exigiendo una formación que rebase el simple adiestramiento en las tareas archivísticas.

Como consecuencia de las instituciones que la conforman, la Red Nacional de Archivos de Instituciones de Educación Superior (Renaies), ha podido realizar acciones en ese sentido para expandir la cultura archivística. En la coyuntura presente puede hacerlo promoviendo la formación profesional de los archivistas a nivel superior. Pero esta iniciativa no surgirá de las instituciones educativas sino del gremio, recordemos cómo ha sido la historia de las profesiones. Renaies reúne a universitarios que pueden actuar en este sentido, porque está inmersa en las instituciones y conoce sus reglas, tiene voz en la materia y podría promover como requisito que quienes dirigen archivos tengan título profesional registrado en la Dirección General de Profesiones; ${ }^{6}$ esto garantizará que tales profesionales tengan la capacidad de insertarse en los cuadros directivos de las organizaciones y puedan tomar decisiones.

Es innegable que la archivística tiene justificación social suficiente para integrarse a las instituciones educativas y generar los profesionales que México necesita con urgencia.

6 La Ley de General de Profesiones incluyó ya las profesiones de bibliotecario y archivista en 1948. 


\section{Referencias}

Arce Gurza, Federico, Historia de las profesiones en México, México, El Colegio de México, 1982.

Instituto Federal de Acceso a la Información Pública (IFAI), Diagnóstico de la situación archivística de las dependencias y entidades de la Administración Pública Federal, 2007, en <http://inicio.ifai.org.mx/Publicaciones/ Diagnostico_Archivos.pdf $>$ [consultado en marzo de 20015].

Phillip, Elliot, Sociología de las profesiones, Madrid, Tecnos, 1975.

Ramírez López, Celia. La formación en la UNAM, Pensamiento Universitario, núm. 67, UNAM-CESU, 1986.

"La archivística, un viejo oficio, una nueva profesión", en Teoría y práctica archivistica, México, UNAM-CESU, 2000 (Cuadernos del Archivo Histórico de la UNAM, núm. 11).

Formación permanente de los archivistas, México, ADABI, A. C., 2008. 